\title{
Influence of design on performance of a latent heat storage system for a direct steam generation power plant
}

\author{
Tolga Pirasaci ${ }^{\mathrm{a}, \mathrm{b}, *}$, D. Yogi Goswami ${ }^{\mathrm{a}}$ \\ ${ }^{a}$ Clean Energy Research Center, University of South Florida, Tampa, FL, USA \\ ${ }^{b}$ Department of Mechanical Engineering, Gazi University, Ankara, TURKEY
}

\begin{abstract}
This work focuses on the design of latent heat storage unit for direct steam generation power plants. In this paper a simple model for the design of a storage unit is presented. This model includes phase change of water/steam and the sensible heat stored in phase change material. The effectiveness of the storage is considered as the design criterion in this model and the influence of various design parameters on the effectiveness is explained. Results show that:
\end{abstract}

- Length of storage has a major impact on the effectiveness

- Flow rate of heat transfer fluid is important

- Diameter of the tubes has an impact on the effectiveness

- Distance between tubes does not have significant effect on effectiveness

Keywords: Thermal energy storage, Latent heat storage, Storage design, Direct steam generation, PCM

\section{Nomenclature}

A heat transfer area, $m^{2}$

c specific heat, $\mathrm{J} / \mathrm{kgK}$

$D \quad$ Diameter, $m$

$h \quad$ convection heat transfer coefficient, $W / m^{2} K$

$k \quad$ conduction heat transfer coefficient, $W / m K$

$l \quad$ length of a single tank, $m$

$L \quad$ flow path length, $m$

$\mathbb{L} \quad$ latent heat, $\mathrm{J} / \mathrm{kg}$

$\dot{m} \quad$ mass flow rate, $\mathrm{kg} / \mathrm{s}$

${ }^{*}$ Corresponding author. Tel.:+90 312 5823401; Fax.:+90 3122319810

Email address: pirasaci@gazi.edu.tr (Tolga Pirasaci)

Preprint submitted to Elsevier

September 30, 2015

(C) 2015. This manuscript version is made available under the Elsevier user license http://www.elsevier.com/open-access/userlicense/1.0/ 


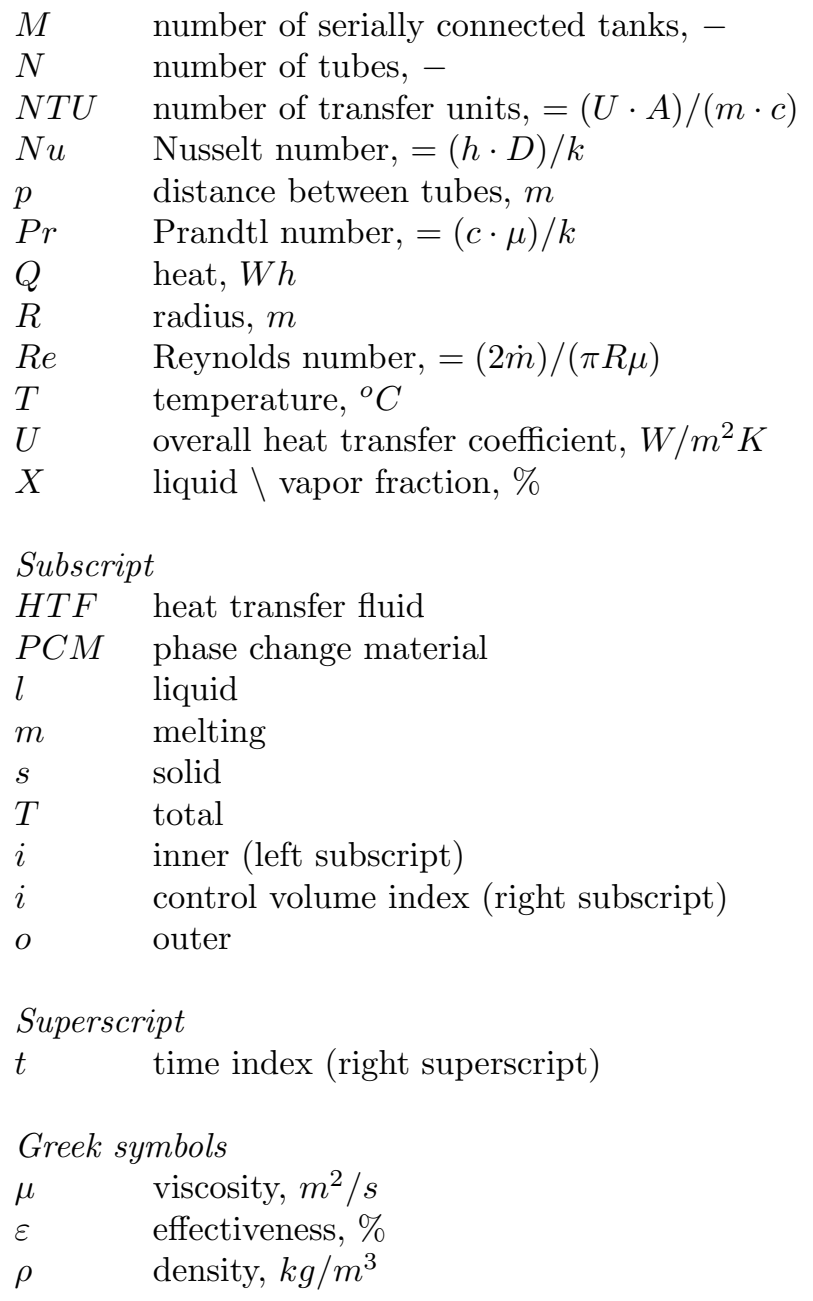

\section{Introduction}

Solar thermal power plants are one of the most suitable renewable energy technologies for electricity generation. In order to extend the use of this technology, it is necessary to reduce costs by increasing efficiency. One way to increase efficiency is to increase the operating temperature. One of the recent technologies used for this purpose is Direct Steam Generation (DSG) in the solar field. In this system water is directly evaporated and superheated in the solar field. DSG plants can only become economically competitive if a cost effective storage system is available $[1,2,3]$.

There are two main types of DSG storage systems reported in the literature: sensible heat storage and latent heat storage.

In sensible heat storage, molten salts are generally used as a heat storage medium. During discharging, the heat from molten salt is transferred to the 
water/steam by using heat exchangers. In this process the high temperature difference between molten salt and water/steam causes lower efficiencies.

In the latent system phase change materials $(\mathrm{PCM})$ is used to store the evaporation enthalpy of water/steam. The temperature profile in the storage system is matched to the temperature profile of the water/steam. Thus higher efficiencies can be obtained in these systems. Four variants of this system (Fig. 1) are explained in the literature $[4,5,6,7,8]$.

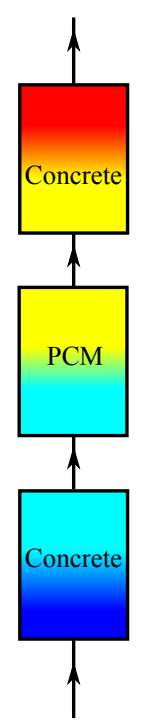

(a)

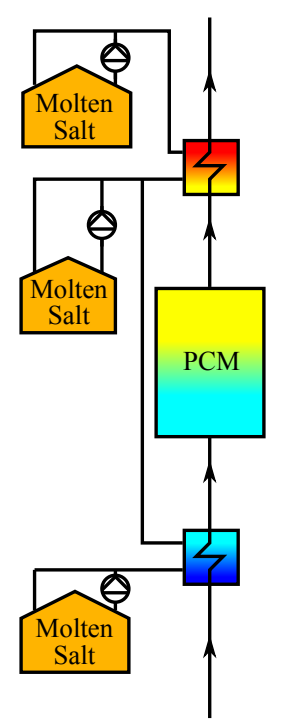

(b)

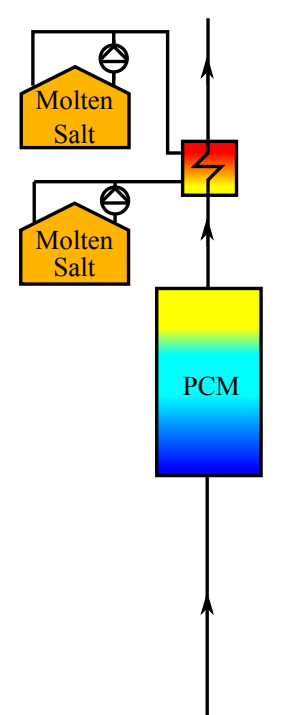

(c)

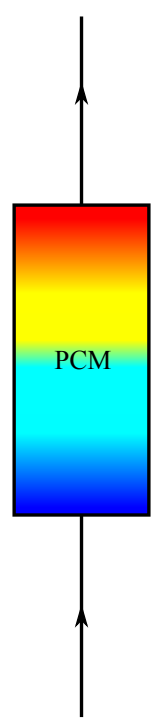

(d)

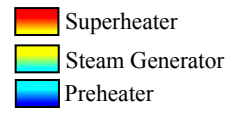

Liquid water
Saturated liquid

Saturated steam

Superheated steam

Figure 1: Variants of modular heat storage systems

Among them Variant-d (PCM-Vd) in which the PCM is used for preheating, steam generation and superheating has the simplest structure (Fig. $1 \mathrm{~d}$ ). Moreover compared to molten salts, PCM has the mass and cost advantages. Also this type of storage does not require expensive heat exchangers, pumps and freeze protection.

Considering these advantages PCM-Vd storage systems seem to be the best option for DSG plants. The present work focuses on the design of PCM-Vd storage unit for direct steam generation power plants.

The basic approach in the design of the heat storage unit is the determination of the amount of storage material to be used for desired storage capacity. For PCM storages the required amount of material $\left(m_{P C M}\right)$ is determined by Eq. $1[9]$. 


$$
m_{P C M}=\frac{Q_{\text {storage }}}{c_{P C M-s} \cdot\left(T_{m}-T_{s}\right)+\mathbb{L}_{P C M}+c_{P C M-l} \cdot\left(T_{l}-T_{m}\right)}
$$

Here $Q_{\text {storage }}$ is the desired storage capacity, $c_{P C M-s}$ and $c_{P C M-l}$ are the PCM specific heat at the solid and liquid states, $\mathbb{L}_{P C M}$ is the latent heat of $\mathrm{PCM}, T_{m}$ is the melting temperature $T_{s}$ is the min. operating temperature and $T_{l}$ is the max. operating temperature.

However, this approach only gives information about the size of the storage unit. The impact of the construction of the unit on system performance cannot be examined by using this approach. Several studies have been conducted to examine the storage unit construction and performance relation. In these studies the similarity between the shell-tube heat exchanger and the heat storage unit is taken into account and starting from heat exchanger design methods [10, 11] a relationship between storage unit construction and performance is obtained.

Trp et al. [12, 13] analyzed the heat transfer phenomenon during paraffin melting and solidification, in a shell and tube thermal energy storage system both numerically and experimentally. Bayon et al. $[14,15]$ presented the experimental measurements of a latent heat thermal storage prototype and identified the differences between the design and experimental data. Laing et al. [16] demonstrated a high temperature PCM storage module for steam generation in a $1 \mathrm{MW}$ test facility for different operating modes. Hosseini et al. [17] presented a combined experimental and numerical study of the thermal behavior and heat transfer characteristics of paraffin during constrained melting and solidification processes inside a shell and tube heat exchanger. Nithyanandam and Pitchumani [18] analyzed the influence of the design and the operating parameters on the dynamic charge and discharge performance of the latent heat thermal energy storage system embedded with gravity-assisted heat pipes. Tay et al. [19, 20] presented the results of CFD analyses of the tube in tank phase change thermal energy storage system for various designs. Seddegh et al. [21] investigated the thermal behavior and heat transfer characteristics of a vertical cylindrical shell and tube latent heat thermal energy storage unit, using a pure thermal conduction model and a combined conduction-convection heat transfer model. Liu et al. [22] presented a design of a cascaded latent heat storage system, which enables a discharge duration of 6 hours for a $50 \mathrm{MWh}$ solar tower power plant. All of these authors obtained similar melting - solidification behavior and specified governing mechanisms of the heat transfer during these processes. They also developed various numerical techniques for solving transient phase change problems. However these numerical techniques require small time steps. As a result simulation of melting and solidification processes takes very long computational time. Therefore, there is a need to develop simple design methods requiring less computational time.

A treatment of sensible heat energy storage unit was presented by Bejan [23]. In this study he considered the storage system consisting of a large liquid bath placed in an insulated vessel. Hot gas enters the system through one port, is cooled by flowing through a heat exchanger immersed in the bath and is eventually discharged into the atmosphere. He obtained the time dependence 
of the bath temperature, the gas outlet temperature, and the storage efficiency during the storage process analytically as a function of heat transfer surface area and fluid (storage bath, heat transfer fluid) properties under the following assumptions.

- specific heat of bath and heat transfer fluid are constant,

- there is no condensation or vaporization during the process,

- the liquid bath is well mixed (isothermal),

- the overall heat transfer coefficient is constant

- the heat capacity of the heat transfer fluid is much smaller than the bath heat capacity.

He mentioned that there exists an optimum relationship among the heat storage design parameters which minimizes the system irreversibility while maximizing its capability of storing useful work.

Lecomte and Mayer [24] presented a method of determining the surface area of a shell and tube heat exchanger and the volume of the phase change material in order to deliver a certain power during a given period. They developed a model with the following assumptions:

- Heat capacity effects of the tubes are neglected.

- Heat capacity of the heat transfer fluid (HTF) is neglected.

- Initial overheating is neglected: the initial temperature of the medium is the phase-change temperature,

- Sensible heat in the PCM is neglected

- No significant interference between adjacent tubes exists as long as the fusion radius has not reached half the space step.

- The heat exchanger may be approximated by a single tube of a certain length.

- The bulk temperature of the HTF depends only on the time and the axial coordinate.

- The heat losses are negligible.

- The Biot number is high enough to neglect the conduction in the radial direction.

- All the thermophysical properties of the HTF and the PCM are constant.

Recent studies about the design of PCM storage systems are reported by Tay et al. $[25,26,27]$. In these studies a simplified mathematical representation was analytically developed for a cylindrical tank filled with phase change material. The mathematical models have the following assumptions. The inlet velocity and inlet temperature of the HTF are constant and the outer walls of the tank are adiabatic. The initial temperature of the latent heat storage unit is uniform and the PCM is in the solid phase for melting or in the liquid phase for freezing. The models are axisymmetric and the thermophysical properties of the HTF, 
the tube wall and the PCM are constant. Natural convection in the liquid phase of the PCM was ignored. They concluded that the simplified technique can readily be used as a design tool for sizing and optimizing a thermal storage unit with phase change materials.

In these studies the heat transfer fluid does not change phase, the sensible heat stored in the PCM is ignored and all thermophiysical properties of PCM and HTF are constant. Under these assumptions the simplified relations between design parameters and performance of the storage are obtained by integrating the energy balances written for a differential control volume in the storage.

Literature survey shows that there is limited information about the influence of the design on the performance of a latent heat storage unit for direct steam generation power plants. In the present work, a simple thermal design model of a latent heat storage unit for direct steam generation is developed. The influences of various parameters on the performance of the storage unit were also studied. The developed model includes phase change of water to steam (HTF) and the sensible heat stored in PCM. In this model a similar approach as described in the literature was used. However, for modeling the phase change process and sensible heat effect, the energy equations were solved numerically. In this method the solution domain was divided into small control volumes and the energy equations were solved for these volumes.

\section{Design Model}

A schematic description of the storage is shown in Fig. 2. The storage consists of $M$ pieces of serially connected insulated tanks filled with the PCM. In this system, the feed water entering the storage is heated by flowing through the $N$ number of tubes immersed in the PCM and becomes superheated steam at the exit. Gradually, the PCM temperature decreases and approaches the feed water inlet temperature.

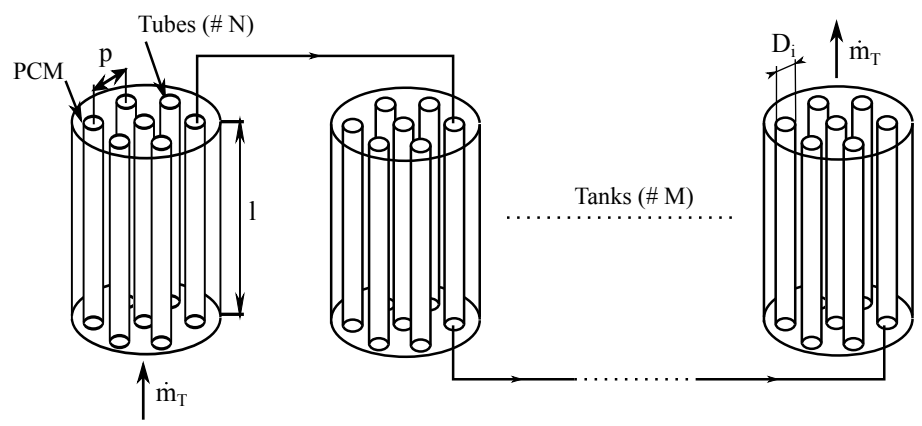

Figure 2: Schematic description of the designed PCM-Vd storage

For simplification, the storage was modeled as a single long tank having a tube at the center. Fig. 3 shows the simplified model of the storage. In this 
model the unknowns of the sizing problem were replaced by the total flow path length $(L=M \times l)$, maximum radius $\left(R_{\max }=p / 2\right)$ and the total mass flow $\left(\dot{m}_{T}=\dot{m}_{H T F} \cdot N\right)$.

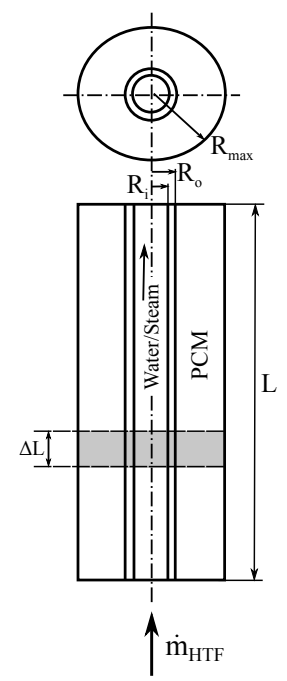

Figure 3: Simplified geometry of PCM-Vd storage

In this figure $R_{i}$ and $R_{o}$ are the inner and outer radii of the tube. The shaded region represents the control volume for the energy balance. This volume is of length $\Delta L$ and heat transfer surface area $\Delta A$. The energy balances and the subsequent analysis were subjected to the following assumptions.

- All the thermophysical properties of the PCM are constant. [23, 24, 25, $26,27]$

- The PCM temperature depends only on time and the axial coordinate. $[25,26,27]$

- Natural convection in the liquid phase of the PCM was ignored. [25, 26, 27]

- The initial temperature of the PCM is uniform. [23, 24, 25, 26, 27]

- Heat capacity effects of the tubes are neglected. [23, 24]

- The temperature of water/steam depends only on the time and the axial coordinate. $[23,24]$

- The outer walls of the tank are adiabatic. [23, 24, 25, 26, 27]

Applying an energy balance to the PCM in a control volume, it follows that

$$
\Delta \dot{Q}=m_{P C M} \cdot c_{P C M} \cdot \frac{\Delta T}{\Delta t} \quad \text { (Sensible cooling) }
$$

and 


$$
\Delta \dot{Q}=m_{P C M} \cdot \mathbb{L}_{P C M} \cdot \frac{\Delta X_{P C M}}{\Delta t} \quad \text { (Solidifying) }
$$

where $\mathbb{L}_{P C M}$ is the latent heat of fusion and $X_{P C M}$ is the liquid fraction of the PCM.

An energy balance on water/steam in the control volume can be expressed as

$$
\Delta \dot{Q}=\dot{m}_{H T F} \cdot c_{H T F} \cdot \Delta T \quad \text { (Sensible heating) }
$$

and

$$
\Delta \dot{Q}=\dot{m}_{H T F} \cdot \mathbb{L}_{H T F} \cdot \frac{\Delta X_{H T F}}{\Delta t} \text { (Boiling) }
$$

where $\dot{m}_{H T F}$ is the mass flow rate, $c_{H T F}$ is the constant pressure specific heat, $\mathbb{L}_{H T F}$ is the latent heat of evaporation and $X_{H T F}$ is the vapor fraction (quality) of water/steam.

The rate of heat transfer in the control volume can also be expressed as

$$
\Delta \dot{Q}=U \cdot\left(T_{P C M}-T_{H T F}\right) \cdot \Delta A
$$

where $U$ is the overall heat transfer coefficient and $T_{P C M}-T_{H T F}$ is the temperature difference between PCM and water/steam.

After solving these equations for a control volume, the temperature and heat transfer distribution were obtained (Table 1).

In these equations subscript $i$ is the control volume index, superscript $t$ is the time index, $N T U$ is the number of transfer units, $k$ is the conduction heat transfer coefficient of the tube and $h$ is the convection heat transfer coefficient. In this work $h$ was calculated by using well known convective heat transfer correlations for circular tubes in the literature $[28,29]$ according to local Reynolds $(R e)$, Prandtl $(\mathrm{Pr})$ and Nusselt $(\mathrm{Nu})$ numbers as follows:

$$
\begin{gathered}
{ }_{i}^{t} h={ }_{i}^{t} N u \cdot{ }_{i}^{t} k / 2 R_{i} \\
{ }_{i}^{t} N u= \begin{cases}3.66 & \text { for laminar flow } \\
\frac{(f / 8)\left({ }_{i}^{t} R e-1000\right){ }_{i}^{t} P r}{\left.1+12.7 /(f))^{0.5}\left({ }_{i}^{t}\right)^{2 / 3}-1\right)} & \text { for turbulent flow }\end{cases} \\
{ }_{i}^{t} R e=2 \dot{m}_{H T F} /\left({ }_{i}^{t} \mu R_{i} \pi\right) \\
{ }_{i}^{t} P r={ }_{i}^{t} c_{H T F} \cdot{ }_{i}^{t} \mu /{ }_{i}^{t} k
\end{gathered}
$$

In the simulations these equations were solved using Matlab and the distributions of the temperature and the heat transfer were obtained. Once the heat transfer rates are computed, the effectiveness of storage, $(\varepsilon)$ can be determined by using (29)

$$
\varepsilon=\frac{Q_{\text {used }}}{Q_{\text {storage }}}=\frac{\sum_{t} \sum_{i}^{t} \dot{Q}}{Q_{\text {storage }}}
$$


Table 1: Heat transfer relations

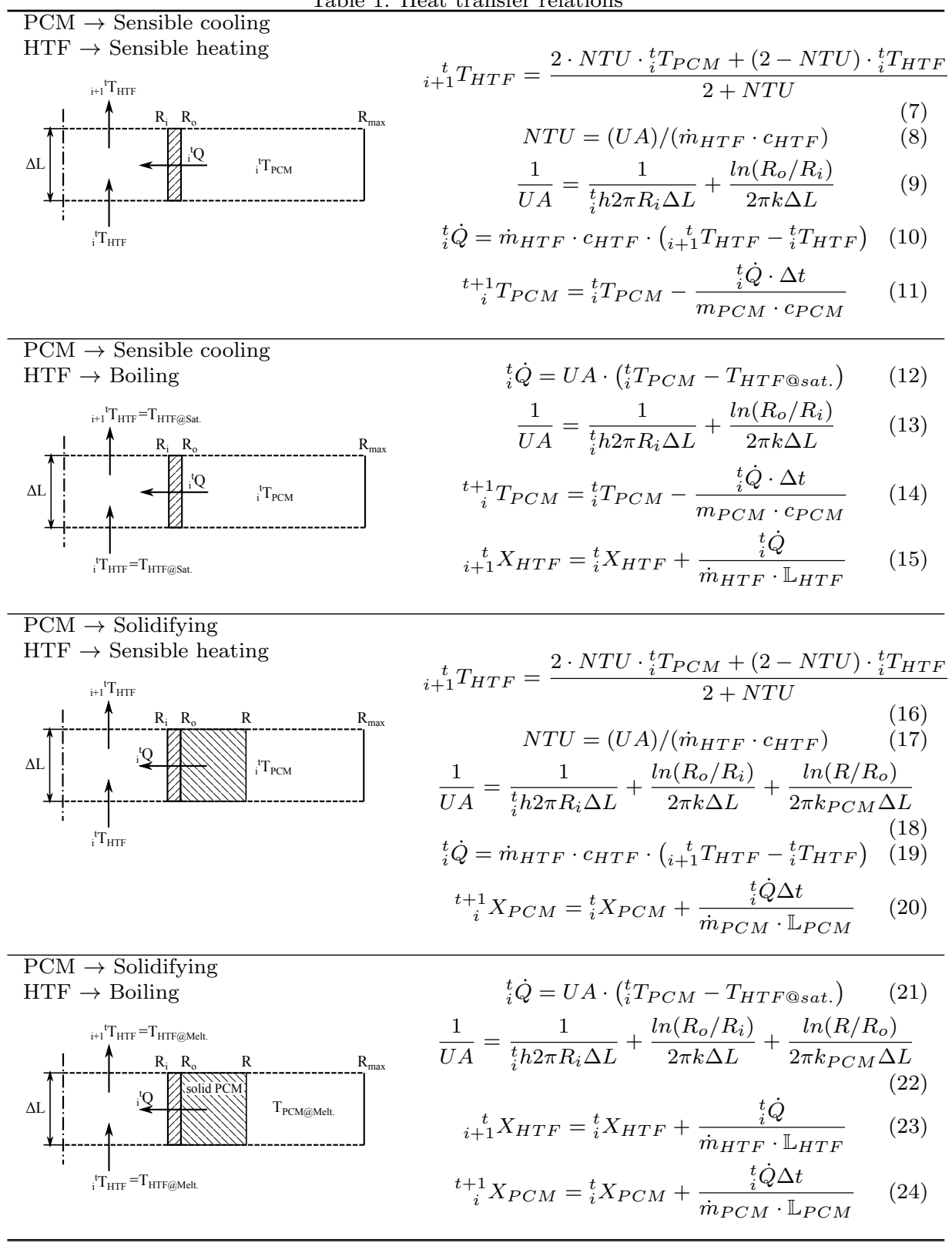

where $Q_{\text {used }}$ is the used heat during discharging and $Q_{\text {storage }}$ is the storage capacity. 


\section{Design and Optimization}

In this study the discharging process is modeled for a PCM storage for DSG solar power plant applications with $325^{\circ} \mathrm{C}$ feed water inlet and $580^{\circ} \mathrm{C}$ superheated vapor exit temperatures at $165 \mathrm{bar}$ water/steam pressure. $\mathrm{NaCl}-\mathrm{MgCl}_{2}$ eutectic mixture is used as the storage medium. Thermophysical properties of this mixture are: melting temperature of $549^{\circ} \mathrm{C}$, latent heat of $316 \mathrm{~kJ} / \mathrm{kg}$, thermal conductivity of $0.95 \mathrm{~W} / \mathrm{mK}$, specific heat of $1000 \mathrm{~J} / \mathrm{kgK}$. Initially the PCM is in the liquid phase having $600^{\circ} \mathrm{C}$ temperature.

To investigate the influence of various design parameters on the performance of the storage unit analyses were conducted for the combination of parameters given in Table 2.

Table 2: Analyzed study parameters

\begin{tabular}{lccc}
\hline \multicolumn{3}{c}{ Table 2: Analyzed study parameters } \\
\hline$D_{i}($ in $)$ & $p-D_{i}($ in $)$ & $R e_{H T F}(-)$ & $L(m)$ \\
\hline 1 & 1 & 635 & 10 \\
2 & 2 & 3178 & 20 \\
& 3 & 6357 & 30 \\
& 31786 & 40 \\
& & $:$ \\
& & 140 \\
\hline$D_{i}:$ inner diameter (Fig. 2) & 150 \\
$p:$ distance between tubes (Fig. 2) \\
$L:$ flow path length (Fig. 3) \\
$R e_{\text {HTF }}$ : Reynolds number at the entry
\end{tabular}

In these analyses the discharging process starts from the fully charged state of the storage. At this state the PCM is considered to be at a uniform temperature of $600^{\circ} \mathrm{C}$. Under these conditions, the analysis shows that the numerical results did not change for control volume lengths $\Delta L$ of $0.01 \mathrm{~m}$ and smaller. Therefore, the analyses were performed for the control volume length of $0.01 \mathrm{~m}$. The PCM temperature evaluation at various heights and tube lengths in the storage unit during discharging is shown in Fig. 4.

As shown in Fig. 4 during discharging, heat is transferred from PCM to water/steam decreasing the PCM temperature. This decrease continues until the PCM temperature reaches the melting temperature. At this temperature the PCM solidifies releasing its latent heat. Once it completely solidifies the temperature decreases again. This decrease continues until the PCM temperature becomes equal to the feed water inlet temperature. These changes in PCM temperature effect the exit temperature of steam. When the exit temperature of steam falls below $580^{\circ} \mathrm{C}$ it is not considered to be useful for the turbine. Simulations were terminated at this point. The temperature distributions along the storage unit are shown in Fig. 5.

It is seen from the figure that during the discharging process, some of the PCM cools to the feed water inlet temperature at the end of this process. The 

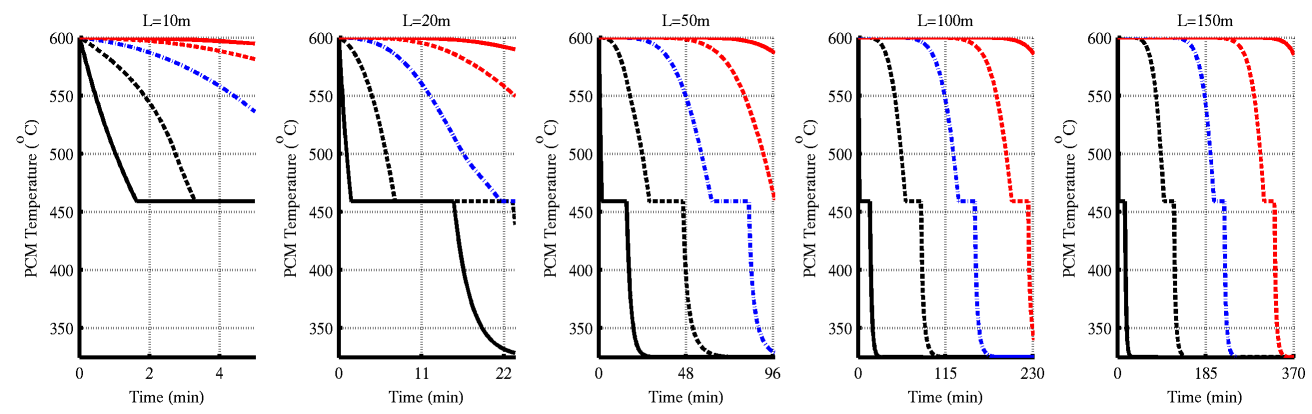

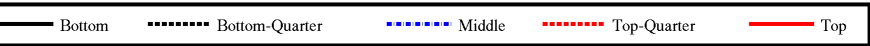

Figure 4: Temperature evaluation of PCM during discharging for ${ }_{1}^{t} R e=3178\left(D_{i}=1^{\prime \prime}\right.$, $\left.p=2^{\prime \prime}\right)$
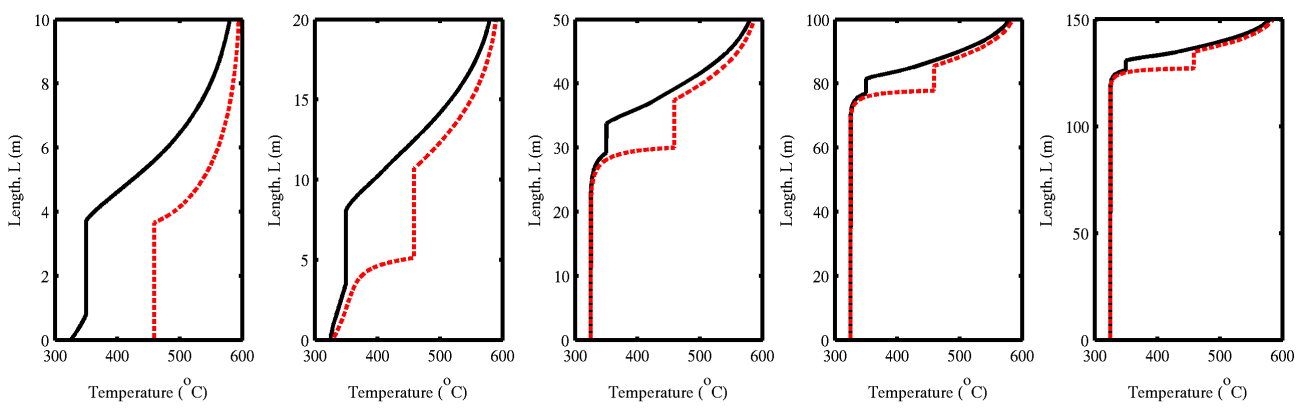

W Water/Steam $\quad$-........ PCM

Figure 5: Temperature variations along storage for ${ }_{1}^{t} R e=3178\left(D_{i}=1^{\prime \prime}, p=2^{\prime \prime}\right)$

volume occupied by the cold PCM (at feed water inlet temperature) increases as the length is increased.

The effect of length on the storage effectiveness is shown in Fig. 6 for various entrance Re numbers, ${ }_{1}^{t} R e$.

This figure shows two interesting results: First the effectiveness of the storage increases by increasing storage length for all flow rates. This is because most of the stored energy in the long storage can be used during discharging process. As clearly seen from the figure, effectiveness increases from $\sim 20 \%$ to $\sim 90 \%$ by increasing the length from $10 \mathrm{~m}$ to $150 \mathrm{~m}$. This makes the length to be an important design parameter. Another interesting result is that by increasing flow rate (Re number) effectiveness increases at first and than decreases. This behavior is explained in more detail in Fig.7.

In Fig. 7.a the change in effectiveness with flow rate $\left({ }_{1}^{t} R e\right)$ is shown for various lengths. Fig. 7.a reveals that the effectiveness has the maximum value at ${ }_{1}^{t} R e=1271$ for all lengths. For the explanation of this behavior the distribution 


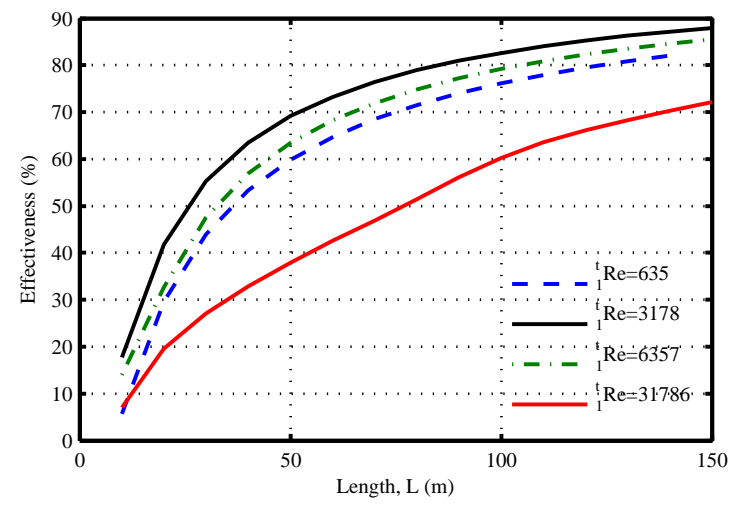

Figure 6: Effect of length on effectiveness $\left(D_{i}=1^{\prime \prime}, p=2^{\prime \prime}\right)$

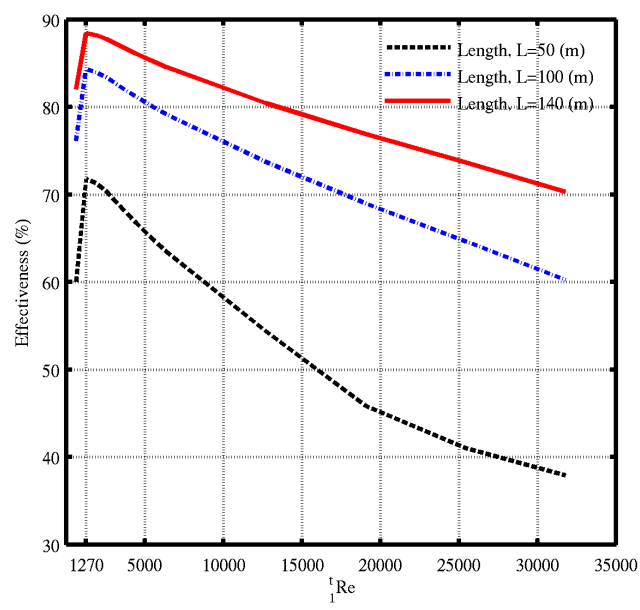

(a)

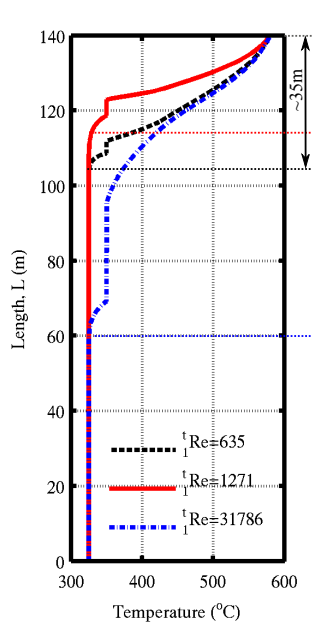

(b)

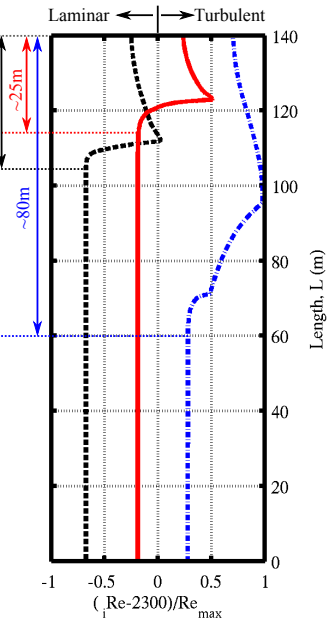

(c)

Figure 7: Effect of flow rate $\left({ }_{1}^{t} R e\right)$ on (a) effectiveness, (b) temperature distribution of water/steam, (c) water/steam flow conditions $\left(D_{i}=1^{\prime \prime}, p=2^{\prime \prime}\right)$

of water/steam temperature and flow conditions along the storage are shown side by side in Fig. 7.b and c. These distributions are plotted at the end of the discharging process for three flow rates $\left({ }_{1}^{t} R e=635,1270,31768\right)$ and $140 \mathrm{~m}$ storage length.

It is seen from Fig. 7.c that the Re number changes along the tube due to the changing thermophysical properties of water/steam during heating.

Here one can see from Fig. 7.c, that for lower flow rates $\left({ }_{1}^{t} R e=635\right)$ the flow along the tube is completely laminar. Under these conditions $\sim 35 \mathrm{~m}$ tube length is required for heating water/steam from $325^{\circ} \mathrm{C}$ to $580^{\circ} \mathrm{C}$ (Fig. 7.b). This means that at the end of the discharging process most of the energy stored 
in the storage is used during discharging giving $82 \%$ effectiveness.

For ${ }_{1}^{t} R e=1271$ however, the flow becomes turbulent during heating due to the changing thermophysical properties of water/steam. This causes an increase in the heat transfer from the PCM to water/steam resulting in a decrease in the required length. In this case $\sim 25 \mathrm{~m}$ is enough to produce steam at the desired condition. As a result, effectiveness reaches its maximum value ( $89 \%$ ) for this flow rate.

Although the flow becomes completely turbulent and heat transfer rates increase with increasing flow rates, the effectiveness of the storage decreases significantly for ${ }_{1}^{t} R e>1271$. This is because heat transfer from the PCM to water/steam becomes insufficient to heat the water/steam at the desired temperature for large flow rates. For ${ }_{1}^{t} R e=31768$ for example $\sim 80 \mathrm{~m}$ of tube length is required for producing $580^{\circ} \mathrm{C}$ steam from $325^{\circ} \mathrm{C}$ feed water resulting $70 \%$ effectiveness.

Other important parameters for the design of storage are the tube diameter, $D_{i}$ and the distance between the tubes, $p$. The effect of these parameters on the effectiveness is explained in Fig. 8

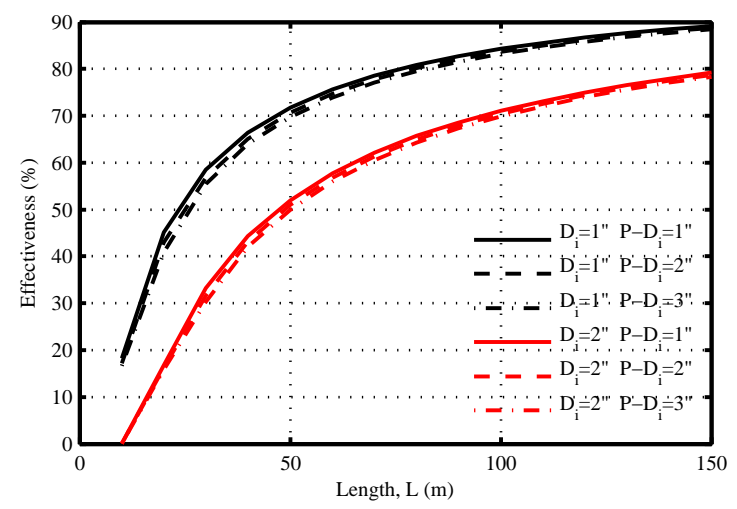

Figure 8: Effect of the tube diameter, $D_{i}$ and the distance, $p$ on effectiveness $\left({ }_{1}^{t} R e=1271\right)$

As shown in Fig. 8 the effectiveness decreases $\sim 10 \%$ with increasing the diameter, $D_{i}$ from 1" to 2 ", and, there is a sight decrease with increasing the distance, $p$. Although this decrease is not significant, stored energy increases significantly due to increasing the storage volume, which should be considered in the selection of $p$ during design.

\section{Conclusion}

In this paper a simple thermal model for the design of a latent heat storage unit for direct steam generation is presented. The effectiveness of the storage is considered as the design criterion in this model and the influence of various parameters on the effectiveness are explained. Results show that: 
- Length of the storage, $L$ has a major impact on the effectiveness. The effectiveness increases with length. The length, L, can be increased by increasing single tank length, $l$ and/or connecting the tanks serially.

- Flow rate ${ }_{1}^{t} R e$ is important. It is found that the effectiveness has an optimum value at ${ }_{1}^{t} R e=1271$. For a certain total flow rate, the number of tubes $(N)$ needs to be calculated such that the ${ }_{1}^{t} R e$ will be 1271 per tube.

- Tube diameter has an important role on the effectiveness. For increasing the effectiveness, it is necessary to use smaller tube diameters. However, smaller diameters cause higher pressure losses, which should be considered in the selection of $D_{i}$ during design.

- Distance between tubes does not have a significant effect on effectiveness but plays an important role on the storage capacity. This should be considered in the selection of $p$ during design.

\section{Acknowledgements}

The work presented herewith has been funded partially by the U.S. Department of Energy through the Advanced Research Projects Agency-Energy (ARPA-E) under the award number: DE-AR0000179. Tolga PIRASACI would like to acknowledge support from The Scientific and Technological Research Council of Turkey (TUBITAK).

\section{References}

[1] J. F. Feldhoff, D. Benitez, M. Eck, and K.J. Riffelmann. Economic potential of solar thermal power plants with direct steam generation compared with htf plants. Journal of Solar Energy Engineering, 132:041001/1-9, 2010.

[2] J. Birnbaum, M. Eck, M. Fichtner, T. Hirsch, and D. Lehmann. A direct steam generation solar power palnt with integrated thermal storage. Journal of Solar Energy Engineering, 132:031014/1-5, 2010.

[3] M. Seitz, P. Cetin, and M. Eck. Thermal storage concept for solar thermal power plants with direct steam generation. Energy Procedia, 49:993 - 1002, 2014.

[4] V. Morisson, M. Rady, E. Palomo, and E. Arquis. Thermal energy storage systems for electricity production using solar energy direct steam generation technology. Chemical Engineering and Processing, 47:499-507, 2008.

[5] W. D. Steinmann and R. Tamme. Latent heat storage for solar steam systems. Journal of Solar Energy Engineering, 130:011004/1-5, 2008. 
[6] D. Laing, T. Bouer, D. Lehmann, and C. Bahl. Development of a thermal energy storage system for parabolic through power plants with direct steam generation. Journal of Solar Energy Engineering, 132:021011/1-8, 2010.

[7] D. Laing, C. Bahl, T. Bouer, D. Lehmann, and W.D. Steinmann. Thermal energy storage for direct steam generation. Solar Energy, 85:627-633, 2011.

[8] L.F. Cabeza, C. Sole, A. Castell, E. Oro, and A. Gil. Review of solar thermal storage techniques and associated heat transfer technologies. Proceedings of the IEEE, 100(2):525-538, 2012.

[9] S. Kuravi, J. Trahan, D. Y. Goswami, M. M. Rahman, and E. K. Stefanakos. Thermal energy storage technologies and systems for concentrating solar power plants. Progress in Energy and Combustion Science, 39(4):285 $-319,2013$.

[10] R.K. Shah and D.P. Sekulic. Fundamentals of Heat Exchanger Design. Wiley, 2002.

[11] K. Thulukkanam. Heat Exchanger Design Handbook, Second Edition. CRC Press, 2013.

[12] A. Trp. An experimental and numerical investigation of heat transfer during technical grade paraffin melting and solidification in a shell-and-tube latent thermal energy storage unit. Solar Energy, 79(6):648 - 660, 2005.

[13] A. Trp, K. Lenic, and B. Frankovic. Analysis of the influence of operating conditions and geometric parameters on heat transfer in water-paraffin shell-and-tube latent thermal energy storage unit. Applied Thermal Engineering, 26(16):1830 - 1839, 2006.

[14] R. Bayon, E. Rojas, L. Valenzuela, E. Zarza, and J. Leon. Explaining the experimental behaviour of a $100 \mathrm{kw}$ thermal storage module with nitrate salts as pcm. In 15th SolarPACES Conference, Berlin, 2009.

[15] R. Bayon, E. Rojas, L. Valenzuela, E. Zarza, and J. Leon. Analysis of the experimental behaviour of a $100 \mathrm{kw}$ latent heat storage system for direct steam generation in solar thermal power plants. Applied Thermal Engineerig, 30:2643-2651, 2010.

[16] D. Laing, T. Bauer, N. Breidenbach, B. Hachmann, and M. Johnson. Development of high temperature phase-change-material storages. Applied Energy, 109:497 - 504, 2013.

[17] M.J. Hosseini, M. Rahimi, and R. Bahrampoury. Experimental and computational evolution of a shell and tube heat exchanger as a $\{\mathrm{PCM}\}$ thermal storage system. International Communications in Heat and Mass Transfer, 50:128 - 136, 2014. 
[18] K. Nithyanandam and R. Pitchumani. Design of a latent thermal energy storage system with embedded heat pipes. Applied Energy, 126:266 - 280, 2014.

[19] N.H.S. Tay, F. Bruno, and M. Belusko. Comparison of pinned and finned tubes in a phase change thermal energy storage system using $\{\mathrm{CFD}\} . A p$ plied Energy, 104:79 - 86, 2013.

[20] N.H.S. Tay, M. Belusko, M. Liu, and F. Bruno. Investigation of the effect of dynamic melting in a tube-in-tank $\{\mathrm{PCM}\}$ system using a $\{\mathrm{CFD}\}$ model. Applied Energy, 137:738 - 747, 2015.

[21] S. Seddegh, X. Wang, and A. D. Henderson. Numerical investigation of heat transfer mechanism in a vertical shell and tube latent heat energy storage system. Applied Thermal Engineering, 87:698 - 706, 2015.

[22] M. Liu, N.H.S. Tay, M. Belusko, and F. Bruno. Investigation of cascaded shell and tube latent heat storage systems for solar tower power plants. Energy Procedia, 69:913 - 924, 2015.

[23] A. Bejan. Two thermodinamic optima in the design of sensible heat units for energy storage. Transactions of ASME, 100:708-712, 1978.

[24] D. Lecomte and D. Mayer. Design method for sizing a latent heat store/heat exchanger in a thermal system. Applied Energy, 21:55-78, 1985.

[25] N.H.S. Tay, M. Belusko, and F. Bruno. Design a pcm storage system using the effectiveness-number of transfer units method in low energy cooling of buildings. Energy and Buildings, 50:234-242, 2012.

[26] N.H.S. Tay, M. Belusko, and F. Bruno. An effectiveness-ntu technique for characteristing tube-in-bank phase change thermal energy storage systems. Applied Energy, 91:309-319, 2012.

[27] N.H.S. Tay, M. Belusko, A. Castell, L.F. Cabeza, and F. Bruno. An effectiveness-ntu technique for characteristing a finned tubes pcm system using a cfd model. Applied Energy, 131:377-385, 2014.

[28] T.L. Bergman, A.S. Lavine, F.P. Incropera, and D.P. DeWitt. Fundamentals of Heat and Mass Transfer, Seventh Edition. Wiley, 2011.

[29] Y. Cengel and A. Ghajar. Heat and Mass Transfer: Fundamentals and Applications, Fifth Edition. McGraw-Hill, 2014. 